\title{
Correlation analysis between vegetation coverage and climate drought conditions in North China during 2001-2013
}

\author{
GONG Zhaoning, ZHAO Shuyi, GU Jinzhi
}

Beijing Laboratory of Water Resources Security; Key Laboratory of 3D Information Acquisition and Application, Ministry of Education; Key Laboratory of Resources Environment and GIS of Beijing; College of Resource Environment \& Tourism, Capital Normal University, Beijing 100048, China

\begin{abstract}
Climate change is one of the most important factors that affect vegetation distribution in North China. Among all climatic factors, drought is considered to have the most significant effect on the environment. Based on previous studies, the climate drought index can be used to assess the evolutionary trend of the ecological environment under various arid climatic conditions. It is necessary for us to further explore the relationship between vegetation coverage (index) and climate drought conditions. Therefore, in this study, based on MODIS-NDVI products and meteorological observation data, the Palmer Drought Severity Index (PDSI) and vegetation coverage in North China were first calculated. Then, the interannual variations of PDSI and vegetation coverage during 2001-2013 were analyzed using a Theil-Sen slope estimator. Finally, an ecoregion perspective of the correlation between them was discussed. The experimental results demonstrated that the PDSI index and vegetation coverage value varied over different ecoregions. During the period 2001-2013, vegetation coverage increased in the southern and northern mountains of North China, while it showed a decreasing trend in the Beijing-Tianjin-Tangshan City Circle area and suburban agricultural zone located in Hebei Province and Henan Province). Over 13 years, the climate of the northeastern part of North China became more humid, while in the southern part of North China, it tended to be dry. According to the correlation analysis results, $73.37 \%$ of North China showed a positive correlation between the vegetation coverage and climate drought index. A negative correlation was observed mainly in urban and suburban areas of Beijing, Tianjin, Hebei Province, and Henan Province. In most parts of North China, drought conditions in summer and autumn had a strong influence on vegetation coverage.
\end{abstract}

Keywords: North China; vegetation coverage; PDSI; ecoregion; correlation analysis

\section{Introduction}

Vegetation coverage can be used as an indicator to show the growth status and tendency of

Received: 2016-08-26 Accepted: 2016-10-09

Foundation: International Science \& Technology Cooperation Program of China, No.2014DFA21620, The China Scholarship Fund

Author: Gong Zhaoning (1976-), PhD and Associate Professor, specialized in remote sensing for natural resources and environment. E-mail: gongzhn@163.com 
vegetation and is also an important parameter that reflects the interactions among the atmosphere, hydrosphere, and lithosphere by mirroring the photosynthetic area and the extent of vegetation growth (Gan et al., 2001). Global climate change has led to significant vegetation changes in the past half century. Researchers have consistently selected vegetation coverage as an important index to evaluate the ecosystem health in view of the impact of global climate change. Drought is an abnormal climate phenomenon reflecting a continuous water deficit. It can synthetically reflect the action of all climate factors on the eco-environment. We define it as the drought index to comprehensively evaluate the extent of climate drought.

Researchers have consistently paid close attention to the relationship between the change in vegetation coverage and the climate drought condition. In the study of vegetation coverage in macroregions, some researchers have analyzed the evolution tendency of vegetation coverage using moderate or low resolution images; other researchers have analyzed the correlation between different climate factors and vegetation coverage. When conducting correlation analysis of the extent of vegetation coverage and meteorological factors or drought index over a time series, a linear correlation equation is generally used to obtain the correlation coefficient. In addition, significant test methods can be used to verify the significance of the correlation. In North China, many researchers have studied the correlation between vegetation cover and climate drought index or climatic factors. Sun et al. (2012) used Global Inventory Modeling and Mapping Studies (GIMMS) Normalized Difference Vegetation Index (NDVI) data from 1982 to 2006 to reflect the time series characteristics of vegetation coverage in North China. The relationship between vegetation coverage and climatic variations at yearly, seasonal, and monthly time scales were analyzed together with temperature and precipitation data from 85 meteorological sites. Wang et al. (2014) analyzed the interannual variability of vegetation NDVI, temperature, and precipitation using NOAA/AVHRR NDVI and 56 meteorological stations over the period from 1982 to 2006 in North China. The response of NDVI to temperature and precipitation at seasonal, monthly, and growing season time scales was also analyzed. Based on GIMMS NDVI data and basic meteorological data from 1981 to 2006, Liu et al. (2015) studied the temporal and spatial variation characteristics of vegetation coverage and explored the impact of human activities on vegetation coverage in North China using trend analysis, residual analysis, and relative role analysis. Mu et al. (2012) used MODIS-NDVI data and climate data such as precipitation and temperature to analyze vegetation dynamics and their relationship with climate change at different spatial (forest, grassland, and desert biome) and temporal (yearly and monthly) scales in Inner Mongolia from 2001 to 2010. The correlation analysis between vegetation coverage and climate showed that annual vegetation coverage was better correlated with precipitation, while the change in monthly vegetation coverage was consistent with changes in both temperature and precipitation, indicating that vegetation growth within a year is more sensitive to the combined function of hydrothermal factors rather than a single climate factor.

Based on the correlation analysis results between vegetation coverage and meteorological factors, drought index, and even the hydrological index, some studies suggest that the effects of different seasonal climatic conditions on vegetation also differ. In analyzing the vegetation coverage and drought index, we paid attention to the correlation between drought in different seasons and different types of vegetation. Wang et al. (2003) studied the correlation 
between NDVI and climatic factors, in particular precipitation and temperature in the central Great Plains, USA. The results showed that average growing season (March-October) NDVI values were highly correlated with precipitation received during the current growing season and seven preceding months (15-month duration). During the early and late stage, NDVI was positively correlated with temperature, but in the middle of the growing season, NDVI was negatively correlated with temperature. Based on NDVI data, Yu et al. (2003) studied the changes in NDVI in different seasons and discussed the response relationship between NDVI and climatic variability. Zheng et al. (2009) analyzed vegetation cover and its relationship with climate change factors in Guizhou from 1987 to 2003 and considered that NDVI and temperature in spring were significantly correlated on a seasonal scale, and the correlation coefficients in spring were higher than in other seasons. Li et al. (2012) believed that the correlation coefficient between NDVI and air temperature was higher than that between NDVI and precipitation in the East China region and its surrounding areas, and the NDVI and temperature were highly correlated in summer and autumn; NDVI and precipitation exhibited a high correlation in spring and autumn.

In large study areas, the ecological environment in response to the degree of surface drought climate is different because of the differences in the surface ecological environment. Therefore, climate change and vegetation distribution characteristics of various types of large intra-regional ecosystems need to be analyzed from a more detailed perspective. According to the guidelines of the ecological system partitioning, based on the difference between the natural surface topography, water and heat conditions, and vegetation cover types, large areas can be classified into different ecoregions. Thus, it is possible to analyze the impact of climate condition on the ecological environment from the perspective of ecoregions.

In this study, MODIS NDVI products were used to obtain vegetation coverage in North China from 2001 to 2013, and the drought index in North China was obtained by combining data from a basic meteorological weather station over the same period. The response of vegetation cover change to the degree of drought and the driving effect of climatic conditions on regional ecosystem changes in North China in different ecological areas were analyzed and discussed. In addition, the correlation between the drought degree and surface vegetation cover was also investigated.

\section{Data and methods}

\subsection{Study area}

According to the outline of the administrative division in North China, the study area contained five provinces or municipalities, including Beijing, Tianjin, Hebei, Henan, and Shandong (Figure 1).

There is undulating terrain in northern North China, which slopes from south to north, most of which is higher than $1000 \mathrm{~m}$ above sea level, with an average annual temperature of -0.3 to $3.5^{\circ} \mathrm{C}$, and annual rainfall of $340-450 \mathrm{~mm}$. The climate of the central North China Plain is a warm temperate continental monsoon, with an average annual temperature of $5-13^{\circ} \mathrm{C}$ and an average annual precipitation of $500-800 \mathrm{~mm}$. In the eastern part of North China, the landscape is dominated by low hills with an elevation of 500-1000 m, annual 


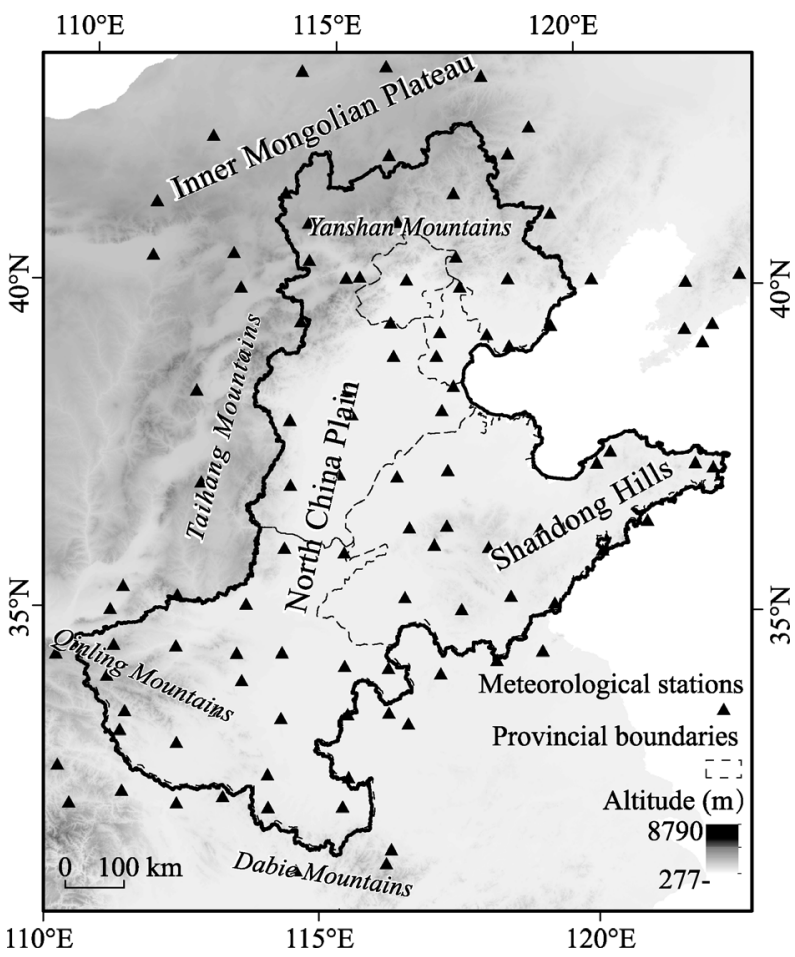

Figure 1 The study area in North China and the distribution of meteorological stations average temperature of $10-13^{\circ} \mathrm{C}$, and annual precipitation of $600-900 \mathrm{~mm}$. The hilly mountainous region in the south of Shandong Province is considerably hot; the hilly area in east of Shandong Province includes the entire Shandong Peninsula and extends southward to the southeast of the provincial boundary; the ocean climate is fairly mild in winter, rather cool, and experiences rainfall. The western Region includes the eastern side of Taihang Mountains, with an average annual temperature of $3-18^{\circ} \mathrm{C}$, excellent annual rainfall 400-800 $\mathrm{mm}$, and superior hydrothermal conditions; the Jixi Mountain elevation exceeds $1000 \mathrm{~m}$; this area is distributed between the mountains in the northern mountainous small basins with an altitude of $300-400 \mathrm{~m}$. The southwestern mountain region belongs to the east extension of Qinling Mountains including Xiao Mountain, Xiong'er Mountain, Funiu Mountain, etc.; the altitude 1500-2000 m, with an average annual temperature of $12-15^{\circ} \mathrm{C}$ and precipitation of $800-1000 \mathrm{~mm}$. The mountainous southern region includes Tongbai Mountain and Dabie Mountain, at an altitude of about $800 \mathrm{~m}$, with an average annual temperature of $13-15^{\circ} \mathrm{C}$, and annual precipitation $1000-1300 \mathrm{~mm}$; this is one of North China's richest areas in terms of heat and water resources.

The study area includes four types of climate zones (Gu et al., 1991; Zheng et al., 2010) and three vegetation zones (Sun et al., 1998). The climate zones of North China include the temperate semi-arid region of the Inner Mongolian Plateau, the warm temperate humid area of the east Liaoning hilly region, the warm temperate semi-humid region of Yanshan Mountains, the North China Plain and east Shandong Province, the north subtropical humid zone of the Dabie Mountains and the Qinling-Daba Mountains. Subdivision vegetation zones include the adjacent portion of the Inner Mongolian Plateau in the northern temperate grassland and mountain areas in northern Hebei, the North China Plain, the western extension of the Taihang Mountains foothill, the Qinling Mountains and warm temperate deciduous broad-leaved forest zone, southwestern Henan, and the northern subtropical evergreen mountainous area south of Henan with a mixed deciduous broad-leaved forest zone.

\subsection{Ecological zoning}

According to the classification standard of Chinese ecological regions from the China Ecosystem Assessment and Ecological Security Database, the study area was divided into seven ecoregions (Figure 2), from north to south, as follows: East Central Inner Mongolian Plateau 
Typical Steppe Ecoregion, Yanshan-Taihang Mountains Deciduous Forest Ecoregion, Tianjin -Beijing-Tangshan Urban and Suburban Agricultural Ecoregion, North China Plain Agricultural Ecoregion, Liaodong-Shandong Hilly Deciduous Broad-leaved Forest Ecoregion, Qinling-Daba Mountains Deciduous and Evergreen Broad-leaved Forest Ecoregion, Huaiyang Hilly Evergreen Broad-leaved Forest Ecoregion. Among them, the area of North China Plain Agricultural Ecoregion accounted for the largest proportion, 34\%; the most northern part of the East Central Inner Mongolian Plateau Typical Steppe Ecoregion only accounted for $3 \%$.

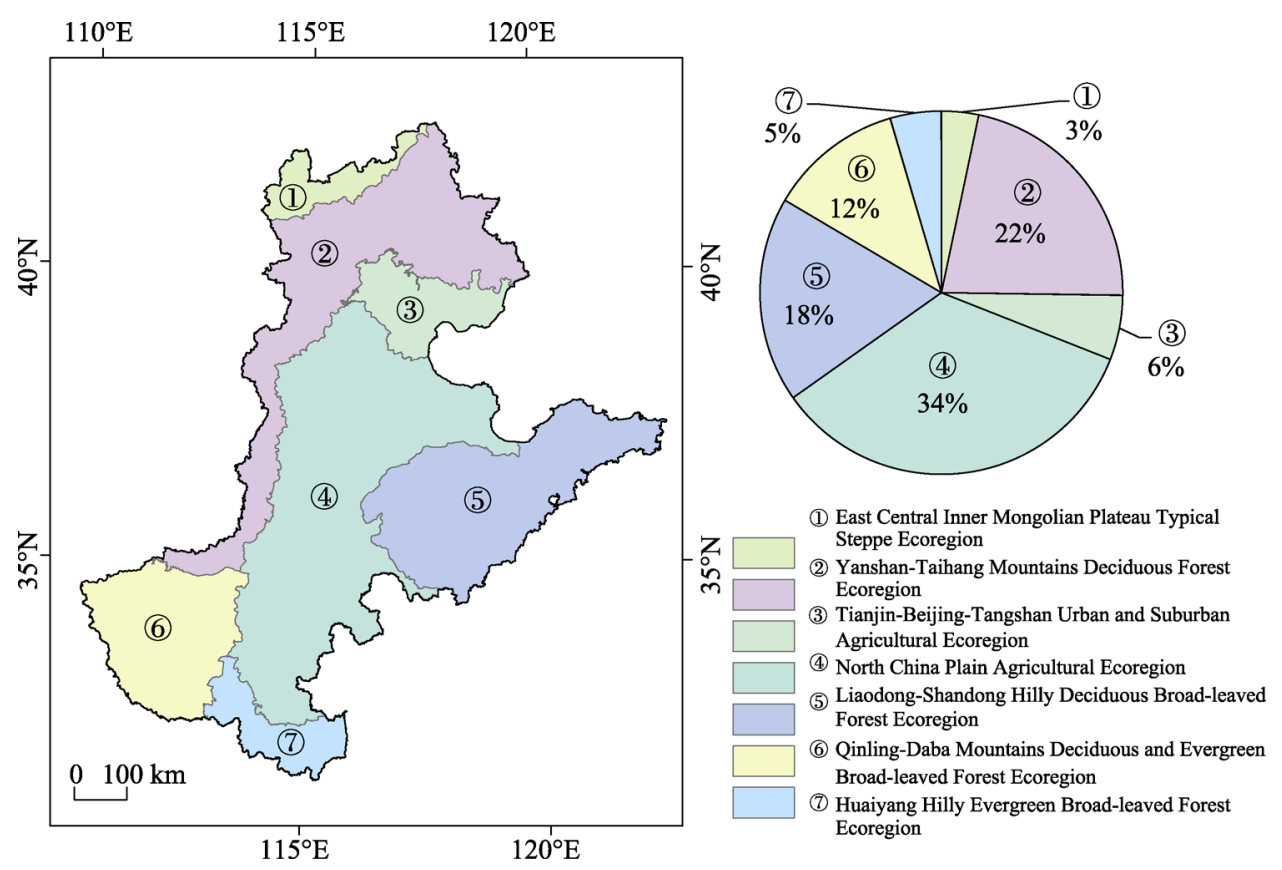

Figure 2 The ecoregion regionalization map and the area proportion of each ecoregion in North China

\subsection{Data sources and preprocessing}

MODIS NDVI daily data products (16 days, $250 \mathrm{~m}$ ) were used in this study. The data serial numbers in the global sinusoidal projection system are h26v04, h26v05, h27v04 and h27v05. In order to exclude the seasonal impact of crop over a year, this article focuses on the growth season from May to October; therefore, data from May 1 to October 31, 2001-2013 were selected. We used the maximum value from the ENVI synthesis (Maximum Synthesis Method, MVC) calendar NDVI data processing, after removing the influence of clouds, atmosphere, and solar elevation angle (Holben et al., 1986; Piao et al., 2001), to obtain the 13-year NDVI value used to calculate the vegetation coverage. The study area range vector interception was used to obtain annual North China and various ecoregion NDVI data.

The daily average air temperature, barometric pressure, relative humidity, wind speed, and sunshine hours, and basic monthly meteorological data from 1964 to 2013 were obtained from the China Meteorological Data Sharing Service System based on MODIS data, data quality and 100 weather stations located in North China and its surrounding areas (Figure 1). 
Vector data for the ecoregions in North China were obtained from the Chinese Ecosystem Assessment and Ecological Security Database. Criteria for the Chinese ecoregions were primarily based on the Fundamental Data of the regionalization of ecological function, issued previously by the National Key Laboratory of Urban and District; reference was also made to the Ecological Function Zoning (interim) Regulations issued by the State Environmental Protection Administration.

\subsection{Calculation of vegetation coverage}

The Mixed Pixel Decomposition model is a common method of calculating the vegetation coverage. It assumes that a remote sensing image pixel is composed of two parts that contain information on pure vegetation and pure soil. The NDVI value of mixed pixels is the weighted average of the NDVI value of pure soil and pure vegetation (Li et al., 2010).

NDVI is calculated as follows:

$$
N D V I=f_{v} \cdot N D V I_{v e g}+\left(1-f_{v}\right) \cdot N D V I_{\text {soil }}
$$

where $N D V I$ is the vegetation index mixed pixel values; $N D V I_{v e g}$ is the pure vegetation pixel vegetation index value; $N D V I_{\text {soil }}$ is the pure soil vegetation index values as elements; and $f_{v}$ is the vegetation coverage.

Therefore,

$$
f_{v}=\left(N D V I-N D V I_{\text {soil }}\right) /\left(N D V I_{\text {veg }}-N D V I_{\text {soil }}\right)
$$

where $N D V I_{\text {soil }}$ represents the pure vegetation pixelminimum for soil, which is theoretically close to zero; $N D V I_{\text {veg }}$ represent the pure vegetation pixel maximum, which is theoretically close to 1 . In fact, due to weather conditions, vegetation types and distribution, seasonal changes and other factors, $N D V I_{\text {soil }}$ and $N D V I_{\text {veg }}$ can vary to different degrees.

First, the vegetation index value of mixed pixels was obtained from the NDVI data after pre-processing. Then, focusing on the NDVI of the vegetation growing season (June-August) every year, NDVI values were calculated by MVC. A $0.5 \%$ confidence level was used to obtain the maximum and minimum NDVI threshold. $N D V I_{v e g}$ is the average of the maximum $0.5 \%$ NDVI value, and $N D V I_{\text {soil }}$ is the average of the minimum $0.5 \%$ NDVI value. Finally, vegetation coverage images were obtained using formula (2).

\subsection{Calculation of the drought index}

Faced with the choice of a variety of meteorology drought indices, Wei et al. (2003) and Han et al. (2009) compared the PDSI, surface humid index, precipitation anomaly percentage, and standardized precipitation index in China. These authors considered that the PDSI index, although only represented by a limited number of stations, surface structure, and level of information, could reasonably describe the characteristics of drought and the effect of weather conditions on the pre-drought degree and showed good spatial and temporal comparison (Liu et al., 2004). Thus, the PDSI is used here to represent climate drought.

Proposed and defined by Palmer (Palmer, 1965), PDSI is widely used in drought data analysis and the reconstruction and monitoring of drought sequences in the U.S. (Liu et al., 2004). Some researchers constructed the Palmer Drought Severity mode evapotranspiration model according to the climate and surface characteristics of China's environmental features, and using a constant value for soil, proposed a suitable correction for the basic model in 
China (Liu et al., 2004; An et al., 1986; Ma et al., 1993; Liu et al., 1997).

The PDSI corrected for China can be calculated on the basis the following formula (Liu et al., 2004):

$$
x_{i}=0.9331 x_{i-1}+z_{i} / 125.99
$$

where $x_{i}$ is the drought index formula in the $i$-th month and $z_{i}$ is the moisture anomaly index in the $i$-th month.

On the basis of equation (4), the weight factor was modified by the meteorological data of other stations:

$$
\begin{gathered}
K^{\prime}=1.2815 \lg \left(\frac{\overline{P E}+\bar{R}+\overline{R O}}{(\bar{P}+\bar{L}) \bar{D}}\right)+3.3027 \\
K=\frac{581.391}{\sum_{1}^{12} D K^{\prime}} K^{\prime}
\end{gathered}
$$

where $\overline{P E}$ is the average annual value of potential evapotranspiration, $\bar{R}$ is the average annual value of the recharge water amount, $\overline{R O}$ is the average annual value of the runoff, $\bar{P}$ is the average annual value of precipitation, $\bar{L}$ is the average annual value of the water loss amount, $\bar{D}$ is the average of the absolute moisture anomalies, $K$ and $K^{\prime}$ are estimated values of the climatic characteristics.

The final calculated PDSI ranged between -10 to 10 , where a value greater than 1 indicates a humid climate, a value less than -1 indicates drought, and a value between -1 and 1 indicates that the climate is in a relatively normal state (Table 1).

The modified Palmer Drought Severity Model, used here, was based on meteorological data from a total of 100 sites located in Beijing, Tianjin, Hebei, Henan, Shandong, Shanxi, Shaanxi, Inner Mongolia, Liaoning, Jiangsu, Anhui, and Hubei, and a total of 12 provinces and autonomous regions over the period 1964-2013 to generate the discrete distribution of PDSI for North China and the surrounding region.

The ArcGIS geostatistical analysis tool with Kriging spatial interpolation methods was used to generate the PDSI raster data. Conversion of the spatial coordinate system and clipping and vegetation coverage data matching the PDSI vector data was conducted in accor-

\begin{tabular}{|c|c|c|c|}
\hline PDSI & Class & PDSI & Class \\
\hline$\geqslant 4.00$ & Extremely wet & -0.50 to -0.99 & Incipient drought \\
\hline 3.00 to 3.99 & Very wet & -1.00 to -1.99 & Mild drought \\
\hline 2.00 to 2.99 & Moderately wet & -2.00 to -2.99 & Moderate drought \\
\hline 1.00 to 1.99 & Slightly wet & -3.00 to -3.99 & Severe drought \\
\hline 0.50 to 0.99 & Incipient wet & $\leqslant-4.00$ & Extreme drought \\
\hline 0.49 to -0.49 & Near normal & & \\
\hline
\end{tabular}
dance with the scope of the study area.

Table 1 Palmer Drought Severity Index ranges and classes

\subsection{The trend analysis and correlation calculation of vegetation coverage and PDSI}

The Theil-Sen slope estimation is a non-parametric estimation method commonly used for 
long-term trend analysis of vegetation coverage changes. In this paper, the Theil-Sen slope estimation method was used to obtain the vegetation coverage trend and PDSI changes in the study area from 2001 to 2013.

The Theil-Sen slope can be calculated using equation 6:

$$
T S_{\text {slope }}=\text { median }\left(\frac{x_{j}-x_{i}}{t_{j}-t_{i}}\right)
$$

where median is the median function; $x_{i}$ and $x_{j}$ are sequence data that represent vegetation coverage or PDSI in different years; $t_{i}$ and $t_{j}$ are the time-series data corresponding to the sequence data; $n$ is the sequence length; and $i<j<n$.

Analysis of the correlation between vegetation coverage in North China and the PDSI was conducted based on the pixel-scale correlation analysis of vegetation coverage and PDSI, using vegetation coverage and PDSI raster data.

The correlation coefficient of vegetation coverage and PDSI could be estimated using the following equation:

$$
R=\frac{\sum_{i=1}^{n}\left(x_{i}-\bar{x}\right)\left(y_{i}-\bar{y}\right)}{\sqrt{\sum_{i=1}^{n}\left(x_{i}-\bar{x}\right)^{2} \sum_{i=1}^{n}\left(y_{i}-\bar{y}\right)^{2}}}
$$

where the correlation coefficient, between two variables $x$ and $y, x_{i}$ is the vegetation coverage in the $i$-th year, the $y_{i}$ is the average annual PDSI in the $i$-th year.

\section{Results and analysis}

\subsection{Average annual data of the spatial distribution of vegetation coverage in each ecoregion}

According to the 2001 to 2013 vegetation coverage data, the distribution of vegetation coverage in various ecoregions of North China in presented in Figure 3.

The average vegetation coverage of grassy prairie plants in the temperate grassland zone, mainly in the eastern part of the typical steppe of the Inner Mongolian Plateau ecoregion, was low, only 0.61 over the 13 years.

The warm temperate, deciduous, broad-leaved forest zone is mainly located in the mountains around the northern, western, and southern of the North China Plain, and its vegetation coverage was high. The average vegetation coverage area of the north of Yanshan and Taihang Mountains ecoregions and the southwest region of Qinling-Daba Mountains was 0.77 and 0.82, respectively. In northern Hebei Province, mountain birch, aspen, and oak forests dominated the western distribution of the Yanshan Mountains pine oak forest; shrub steppe was widely distributed in the northwestern Hebei basin between the warm temperate, deciduous broad-leaved forest zone and the temperate steppe transition; the Taihang Mountains foothills were sparsely covered with deciduous broad-leaved forest and shrub bushes (Wu et al., 1980); in addition, the mountainous region of western Henan Province, was mainly covered with common vegetation of North China, including some regional vegetation of central and western North China (Liu et al., 1996). 
The average vegetation coverage of agro-ecological zones in North China plains, eastern Liaoning-Shandong hilly deciduous forest ecoregions, and Tianjin-Tangshan urban and suburban areas was $0.80,0.77$ and 0.70 , respectively. Agricultural crops in the North China area had high density and the highest vegetation coverage; the vegetation in the Tianjin-Tangshan area was mainly artificial garden, which accounted for the lowest extent of vegetation cover.

The average vegetation coverage in the Huaiyang evergreen broad-leaved forest ecosystem in the hilly area located in the north subtropical evergreen and deciduous broad-leaved mixed forest zone was 0.84 , the highest regional vegetation coverage of the entire North China area, including deciduous and evergreen broad-leaved forest coniferous forest. The vegetation in Nanyang Basin in the western mountain area was mostly oak forest, aspen, and birch, including small amounts of low-altitude mountain evergreen trees and economic trees; deciduous oak forest dominated the south Henan mountainous region (Kuang et al., 1991).

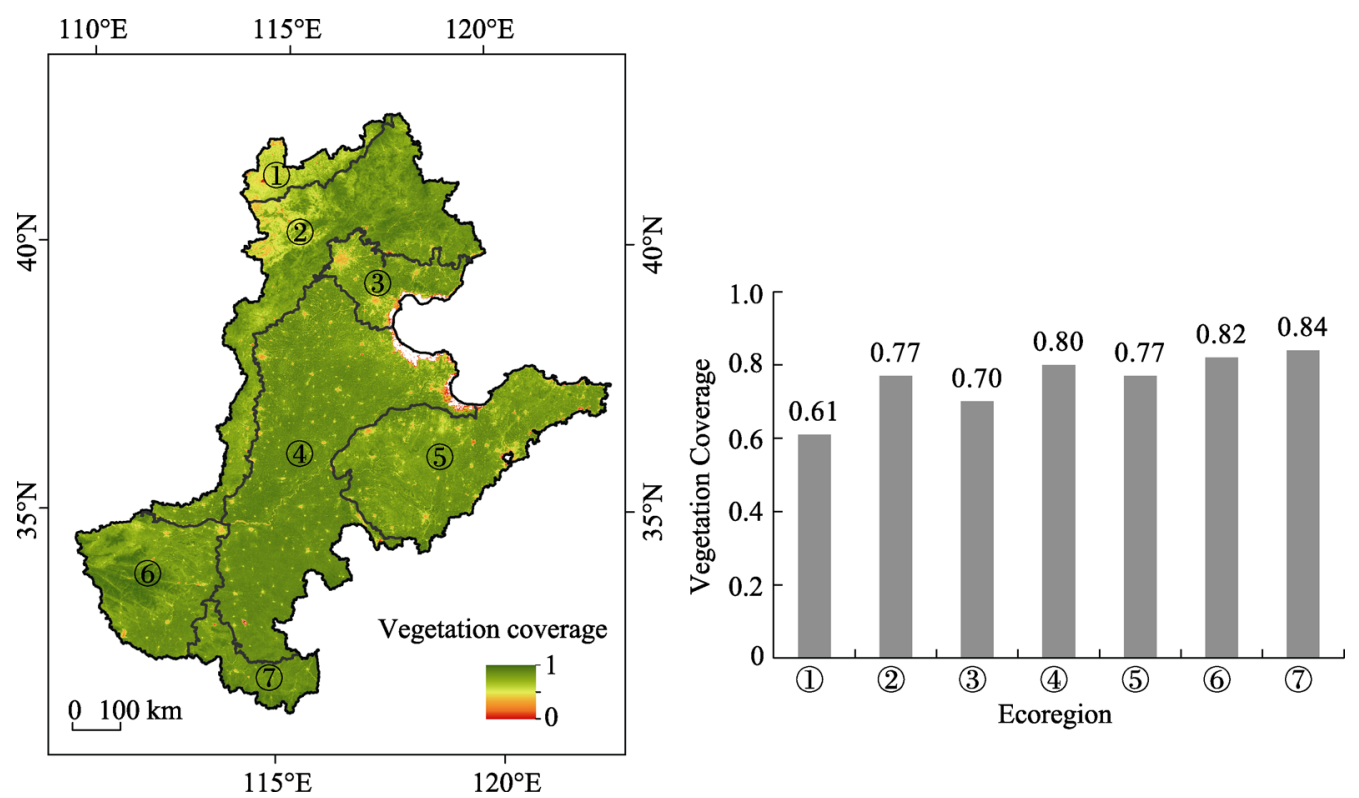

Figure 3 The average vegetation coverage of each ecoregion in North China during 2001-2013

1) East Central Inner Mongolia Plateau Typical Steppe Ecoregion; 2) Yanshan-Taihang Mountain Deciduous Forest Ecoregion; 3) Tianjin-Beijing-Tangshan Urban and Suburban Agricultural Ecoregion; 4) North China Plain Agricultural Ecoregion; 5) Liaodong-Shandong Hilly Deciduous Broad-leaved Forest Ecoregion; 6) Qinling-Daba Mountains Deciduous and Evergreen Broad-leaved Forest Ecoregion; 7) Huaiyang Hilly Evergreen Broad-leaved Forest Ecoregion

\subsection{Vegetation coverage and yearly PDSI trends}

On an annual basis, this paper estimated the trends in the vegetation coverage data and PDSI data from 2001 to 2013.

According to the changes in vegetation cover (Figure $4 \mathrm{a}$ ), the positive and negative trends in the regional study area covered about $2.99 \times 10^{5} \mathrm{~km}^{2}$ and $2.43 \times 10^{5} \mathrm{~km}^{2}$, respectively. Areas with increased vegetation coverage include Yanshan-Taihang Mountains in most parts, hilly evergreen broad-leaved forest ecoregions from the western Liaodong-Shandong hilly ecoregion, the ecoregion near the western mountainous Qinling-Daba regions, and the central part of Inner Mongolian grassland ecoregion. However, the vegetation coverage de- 
creased significantly in the Beijing-Tianjin-Tangshan urban and suburban agro-ecological zones and the western part of the North China agro-ecological zones.

In addition to Beijing, Tianjin and the Inner Mongolian grassland ecoregion in downtown Chinatown, the vegetation coverage in other parts of this 13-year study exhibited a similar trend, i.e., a steady change as low vegetation coverage was evident in 2002, 2006, and 2009 (Figure 5). Over the 13 years, vegetation coverage in the grassland ecoregion of Inner Mongolia exhibited a general increasing trend from 2001 to 2013, increasing from 0.57 to 0.69; from 2005 to 2007, vegetation coverage showed an initial increasing trend followed by a decrease, but volatility from 2008 to 2010 was high and there was a sharp increase after the first decrease. Vegetation coverage in downtown Beijing and Tianjin Chinatown displayed a continuing downward trend, decreasing from 0.74 in 2001 to 0.66 in 2013.
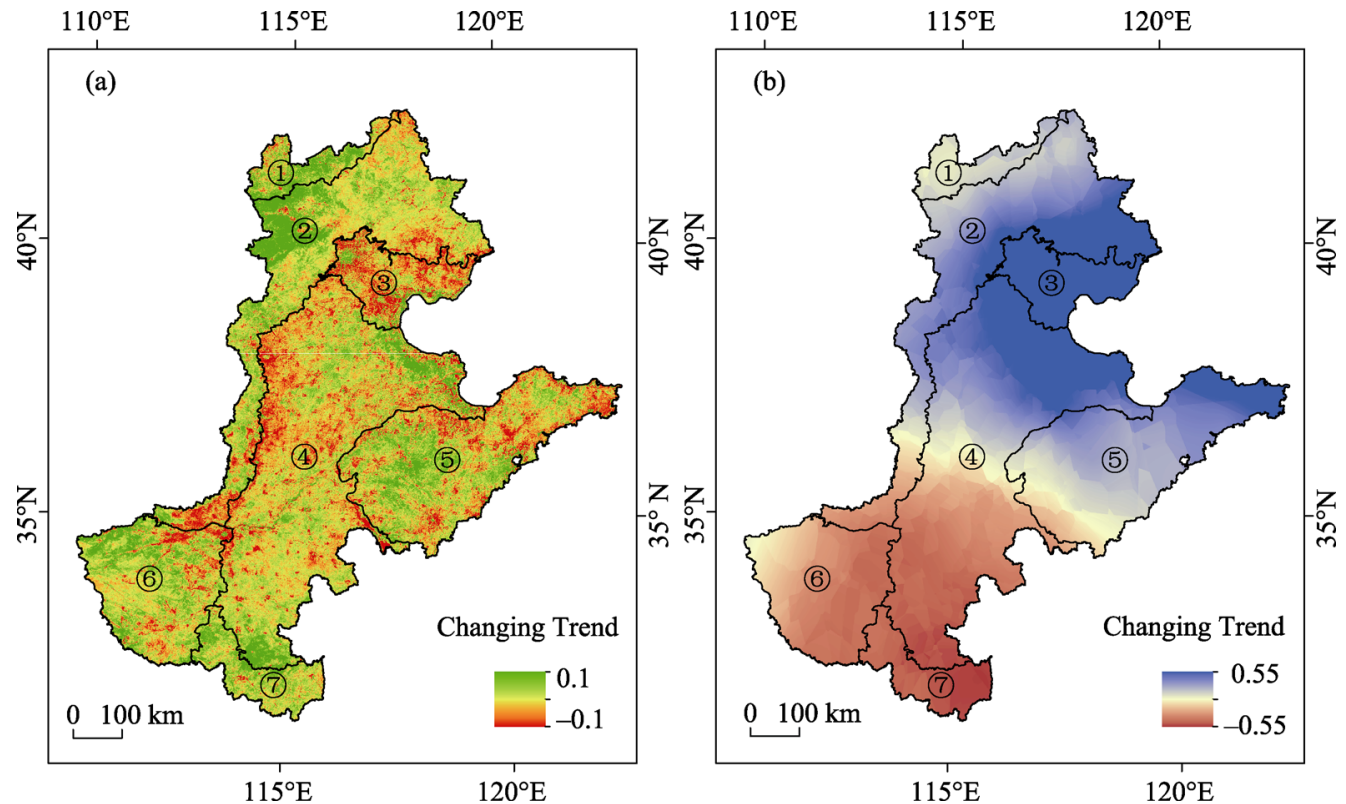

Figure 4 The changing trend of annual vegetation coverage (a) and annual PDSI (b) in North China during 2001-2013

1) East Central Inner Mongolia Plateau Typical Steppe Ecoregion; 2) Yanshan-Taihang Mountain Deciduous Forest Ecoregion; 3) Tianjin-Beijing-Tangshan Urban and Suburban Agricultural Ecoregion; 4) North China Plain Agricultural Ecoregion; 5) Liaodong-Shandong Hilly Deciduous Broad-leaved Forest Ecoregion; 6) Qinling-Daba Mountains Deciduous and Evergreen Broad-leaved Forest Ecoregion; 7) Huaiyang Hilly Evergreen Broad-leaved Forest Ecoregion

The PDSI increasing trend (Figure 4b) in the Yanshan Mountains region, urban and suburban areas of the Tianjin-Tangshan region, the northern part of the North China Plain, and the agricultural region and eastern Shandong hilly area, was explained by the lessening of the meteorological drought conditions. The southern agricultural areas of the North China Plain, southern mountainous parts and western hilly areas of Henan Province displayed a decreasing PDSI trend, indicating an increase in the extent of the drought area.

The PDSI curves for each ecological region over the 13 years were quite different, but except mountainous Qinling-Daba ecoregion and hilly Huaiyang ecoregion, PDSI in the other regions exhibited a clear upward trend (Figure 6). The first decrease in the North 
China PDSI appeared in 2002, in 2002 and 2004, PDSI increased in most parts, while the second decreased appeared in 2006 and 2007, whereas a relatively uniform low value occurred in 2009. PDSI increased in the Inner Mongolian grassland areas and the Yanshan-Taihang Mountains area from 2001 (moderately dry) to 2013 (slightly moist), and in the Beijing-Tianjin-Tangshan region, a severe drought occurred in 2001 whereas 2013 was very wet. PDSI in the Huaiyang hilly evergreen broad-leaved forest ecoregion decreased since 2003, reaching a minimum in 2011, relative to other northern ecoregions that showed a significant lag. In other areas, the PDSI changed little under drought conditions, and drought occurred at a normal level.

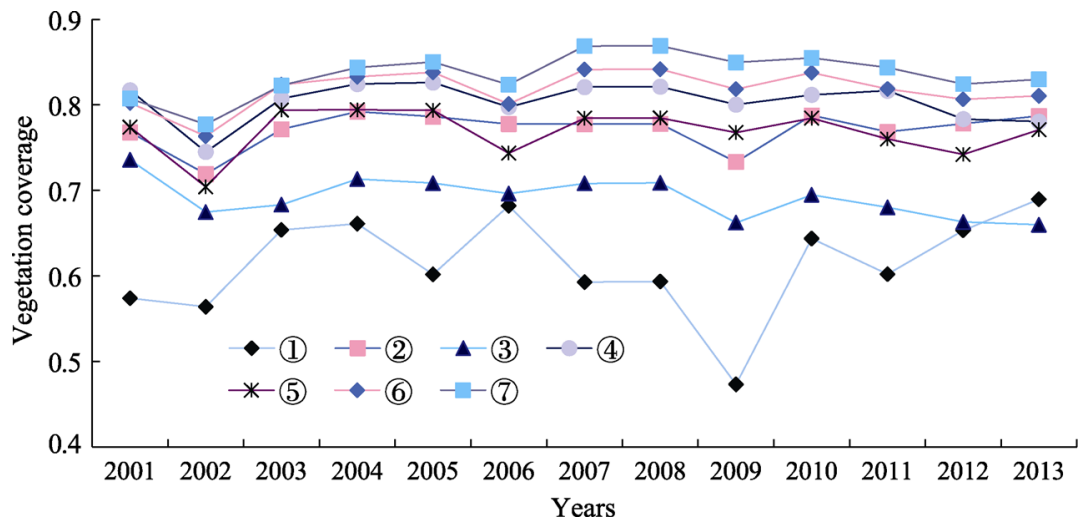

1) East Central Inner Mongolia Plateau Typical Steppe Ecoregion; 2) Yanshan-Taihang Mountain Deciduous Forest Ecoregion; 3) Tianjin-Beijing-Tangshan Urban and Suburban Agricultural Ecoregion; 4) North China Plain Agricultural Ecoregion; 5) Liaodong-Shandong Hilly Deciduous Broad-leaved Forest Ecoregion; 6) Qinling-Daba Mountains Deciduous and Evergreen Broad-leaved Forest Ecoregion; 7) Huaiyang Hilly Evergreen Broad-leaved Forest Ecoregion

Figure 5 The inter-annual change of vegetation coverage in each ecoregion in North China during 2001-2013

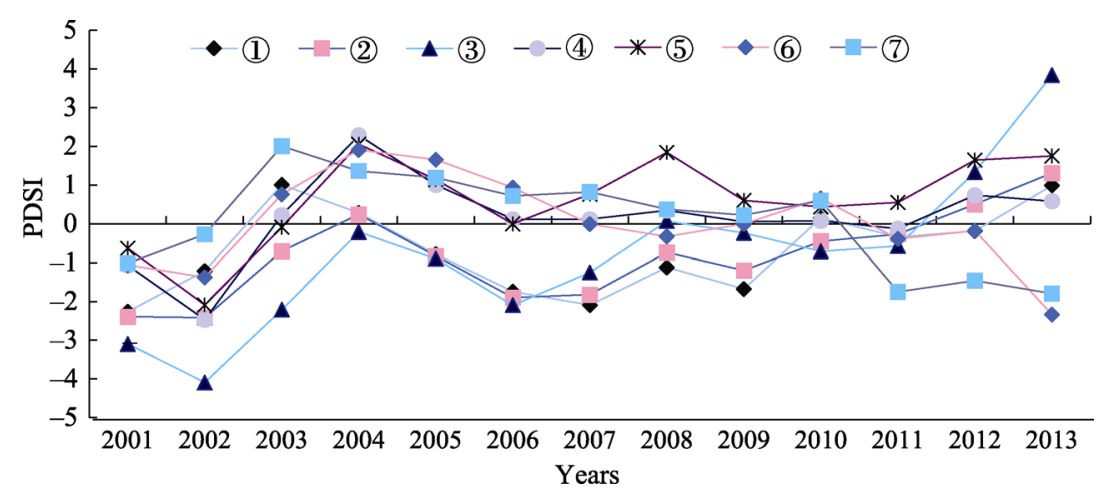

1) East Central Inner Mongolia Plateau Typical Steppe Ecoregion; 2) Yanshan-Taihang Mountain Deciduous Forest Ecoregion; 3) Tianjin-Beijing-Tangshan Urban and Suburban Agricultural Ecoregion; 4) North China Plain Agricultural Ecoregion; 5) Liaodong-Shandong Hilly Deciduous Broad-leaved Forest Ecoregion; 6) Qinling-Daba Mountains Deciduous and Evergreen Broad-leaved Forest Ecoregion; 7) Huaiyang Hilly Evergreen Broad-leaved Forest Ecoregion

Figure 6 The inter-annual change of each ecoregion's PDSI in North China during 2001-2013

According to PDSI and trends analysis based on vegetation coverage of these ecoregions in North China, over the 13 years, there were changes with respect to more unified point mutations, namely in 2002, 2006, and 2009. Therefore, the vegetation coverage in North China exhibits a certain degree of correlation with PDSI. 


\subsection{Relationship with the North China MODIS vegetation coverage}

3.3.1 Correlation Analysis of the average annual PDSI and vegetation coverage in North China

Figure 7 shows the results of equation (7) used in conjunction with the 2001 to 2013 vegetation coverage data and the average annual PDSI data pixel-based correlation analysis. Orange areas indicate where vegetation coverage in North China and the PDSI are positively correlated; the blue areas represent negative correlations between the vegetation coverage and PDSI in North China.
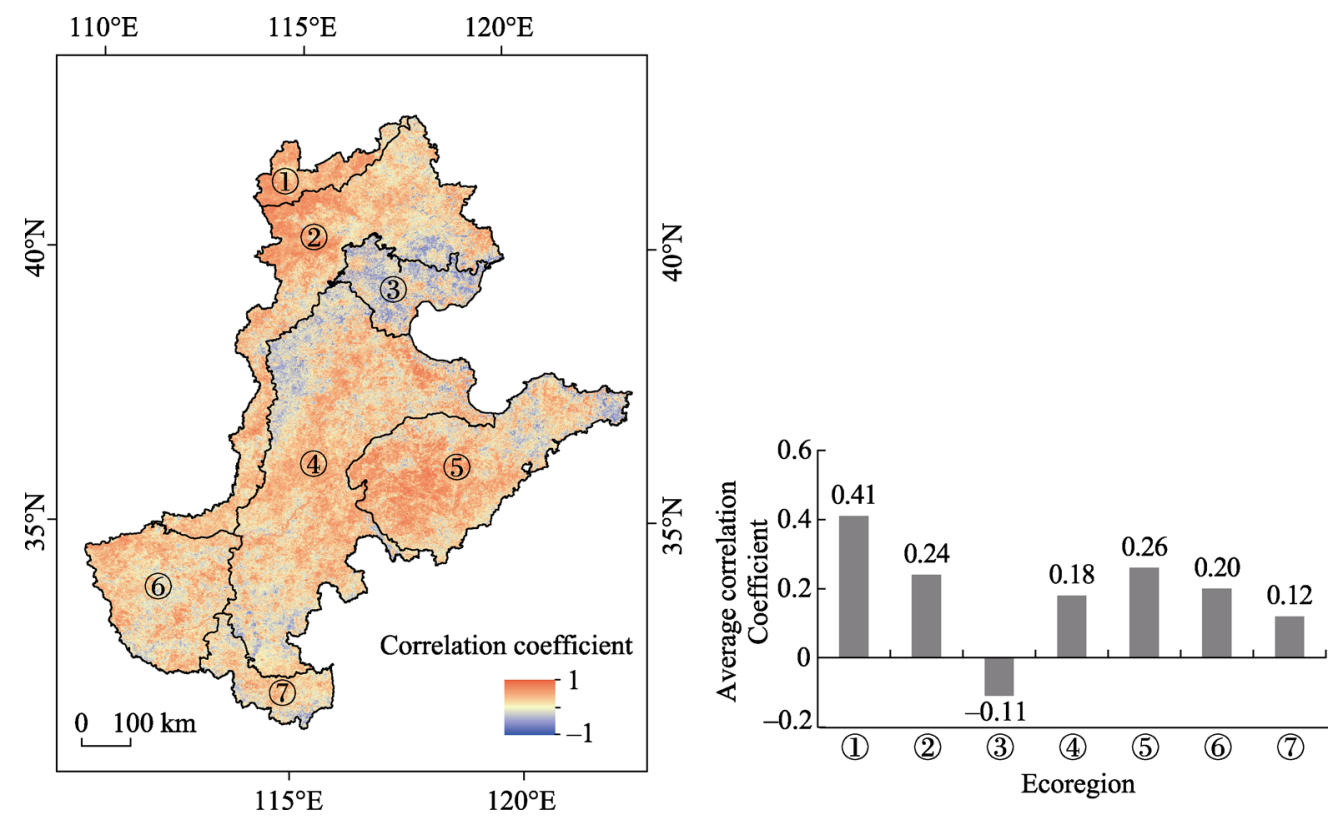

1) East Central Inner Mongolia Plateau Typical Steppe Ecoregion; 2) Yanshan-Taihang Mountain Deciduous Forest Ecoregion; 3) Tianjin-Beijing-Tangshan Urban and Suburban Agricultural Ecoregion; 4) North China Plain Agricultural Ecoregion; 5) Liaodong-Shandong Hilly Deciduous Broad-leaved Forest Ecoregion; 6) Qinling-Daba Mountains Deciduous and Evergreen Broad-leaved Forest Ecoregion; 7) Huaiyang Hilly Evergreen Broad-leaved Forest Ecoregion

Figure 7 Correlation coefficient between vegetation coverage and PDSI in North China during 2001-2013

The average correlation coefficient was 0.20 throughout the study area, and the regional correlation coefficient for the positive and negative regions was $73.37 \%$ and $26.63 \%$, respectively. In the areas with positive correlation, $21.60 \%$ and $10.06 \%$ of the region were significant at $\mathrm{P}<0.05$ and $\mathrm{P}<0.01$, respectively; in the regions with negative correlations, $8.60 \%$ and $2.78 \%$ were significant at $\mathrm{P}<0.05$ and $\mathrm{P}<0.01$, respectively. This shows that there is a relationship between arid climate conditions and vegetation coverage. The correlation coefficients of each ecoregion differ considerably, which needs to be discussed separately for the different regions.

The vegetation coverage area and PDSI were positively correlated for the vast majority of the eastern part of the Inner Mongolian Plateau Ecological typical steppe; a positive correlation coefficient was observed for $94.30 \%$ of the area of the entire region, and the regional average correlation coefficient was 0.41 . 
The vegetation coverage area and PDSI were positively correlated in most areas of the Yanshan-Taihang Mountains deciduous forest ecoregion; the average correlation coefficient was 0.24 for the entire region, of which the positive correlation accounted for $79.05 \%$ of the region, with $18.26 \%$ significant at $P<0.05$. Over the 13 years studied, the extent of the Yanshan-Taihang Mountains area drought lessened and a slightly wet trend was exhibited, but this was not significant, and the vegetation coverage did not change significantly. Stable climate and terrain conditions changed slightly with the extent of the vegetation cover in the area.

In the North China Plain agro-ecological zone, the vegetation coverage and PDSI exhibited a positive correlation coefficient accounting for $71.60 \%$ of the total area; a negative correlation coefficient accounted for $28.40 \%$ of the overall region, the regional average correlation coefficient was 0.18 , and an average correlation coefficient of 0.33 was observed for positive regional trends. From the analysis, it was concluded that the extent of the drought had a relatively large impact on the vegetation coverage, mainly a positive correlation. Negative correlation areas were mainly concentrated in the Taihang Mountains foothill area in contact with the north-south strip, connected to the Tianjin-Tangshan urban and suburban agro-ecological zones.

The average correlation coefficient for the Beijing-Tianjin-Tangshan urban and suburban agro-ecological zones was -0.11 , a negative correlation in this region accounted for $63.54 \%$, of which $19.18 \%$ passed the $\mathrm{P}<0.05$ test. The negative correlation exhibited similar characteristics as the Beijing-Tianjin-Tangshan region, including suburban areas of Baoding, Shijiazhuang, Xingtai, Handan in Hebei Province, Xuchang, Luohe, Zhumadian and other cities in Henan Province. Beijing and the Tianjin region with an arid climate showed a slight improvement compared with a decade ago; the internal urban vegetation coverage of Beijing, Tianjin, and other cities increased, but the city and surrounding suburban vegetation coverage decreased rapidly over the 13 years. Suburban area vegetation coverage exhibited a negative correlation with PDSI; whereas the internal urban vegetation coverage was positively correlated with PDSI, but neither was significant. This ecoregion is considered as urban sprawl and other artificial disturbances are severe, contributing to the low correlation.

The average correlation coefficient in the Liaodong-Shandong hilly deciduous forest ecoregion was 0.26 . The region with a positive correlation coefficient accounted for $78.00 \%$ of the total area, of which $25.63 \%$ of the region was significant at $\mathrm{P}<0.05$; the visible vegetation coverage and PDSI were closely linked, and most of the region presented a significant positive correlation. Over the 13 years studied, drought in the eastern Shandong Province gradually reduced, and that of the southern Shandong Province changed but was not obvious. With the decrease in the extent of drought in the eastern Shandong Province, western and coastal eastern areas of Shandong Peninsula, vegetation coverage decreased. There was a positive correlation coefficient in the southern Shandong Province hilly area, as well as agricultural areas in North China. An increasing number of areas exhibited negative correlations, including the entire Shandong Peninsula extending southward to the southeast of the provincial boundary, at the distribution of the bustling coastal city.

The mountainous deciduous and evergreen broad-leaved forest ecoregions and the Huaiyang hilly evergreen broad-leaved forest ecoregion are regions with the highest degree of vegetation coverage across the entire region of North China. The average correlation coeffi- 
cient for the mountainous ecoregion was 0.20 , a positive correlation coefficient accounted for $75.50 \%$; the average correlation coefficient of the Huaiyang hilly ecoregion was 0.12 , a positive correlation coefficient accounted for $65.77 \%$. We found that the positive correlation between the PDSI and vegetation coverage of these two regions was not related.

3.3.2 Correlation Analysis of the PDSI of North China and vegetation coverage during each season

From a seasonal perspective, the four seasons of the year were set as follows: winter (December of the previous year - February), spring (March-May), summer (June-August) and autumn (September-November). The correlation coefficients of each season are shown in Figure 8 .
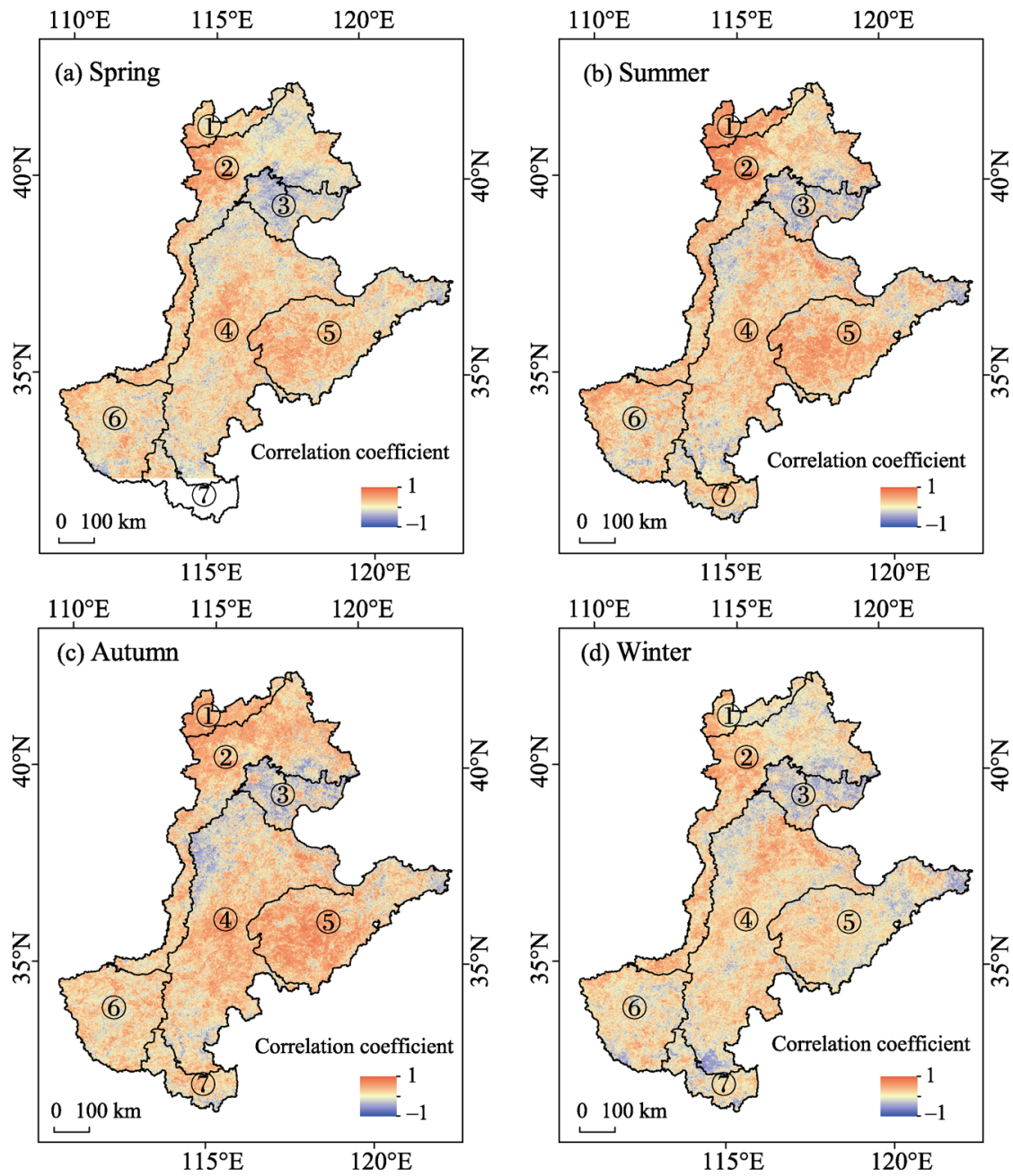

1) East Central Inner Mongolia Plateau Typical Steppe Ecoregion; 2) Yanshan-Taihang Mountain Deciduous Forest Ecoregion; 3) Tianjin-Beijing-Tangshan Urban and Suburban Agricultural Ecoregion; 4) North China Plain Agricultural Ecoregion; 5) Liaodong-Shandong Hilly Deciduous Broad-leaved Forest Ecoregion; 6) Qinling-Daba Mountains Deciduous and Evergreen Broad-leaved Forest Ecoregion; 7) Huaiyang Hilly Evergreen Broad-leaved Forest Ecoregion

Figure 8 Correlation coefficient between vegetation coverage and PDSI in different seasons in North China during 2001-2013 
According to the relevant analytical data for each ecological region (Figure 9), it is obvious that in summer and autumn, the drought in the North China region had the strongest effect on the vegetation coverage.

The strongest correlation coefficients were measured for the vegetation coverage of the typical steppe ecosystem of the eastern Inner Mongolian Plateau and the deciduous forests of the Yanshan-Taihang Mountains ecoregion with respect to the summer and autumn drought index; these values were as high as 0.45 and 0.42 , and 0.25 and 0.24 , respectively, and areas with negative correlations did not exceed $5 \%$ and $20 \%$.

In the four ecoregions, i.e., the North China Plain agro-ecological zone, LiaoningShandong hilly deciduous forest ecoregion, mountainous deciduous and evergreen broadleaved forest ecoregion and the Huaiyang hilly evergreen broad-leaved forest ecoregion, drought in spring, summer, and autumn were influenced by the degree of vegetation cover during the year. The drought of the first three ecoregions in spring, summer and autumn had a lower impact on some of the vegetation coverage; the correlation coefficient for the North China Plain agro-ecological zone in the spring, summer, and autumn did not differ considerably, which to some extent confirms the influence of the North China Plain drought on crops. The results show that in the Huaiyang hilly evergreen broad-leaved forest ecoregion, the greatest effect of the drought on vegetation coverage occurred in spring, followed by summer and autumn, as shown by the correlation coefficient.

The average correlation coefficient for towns in the Tianjin-Tangshan area and the AEZ suburbs was small and negative for all four seasons; a negative correlation was observed across $62 \%-69 \%$ of the area of this ecoregion. The impact of human activities in these areas is considerable, and arid conditions occur naturally; hence, the correlation is not obvious.

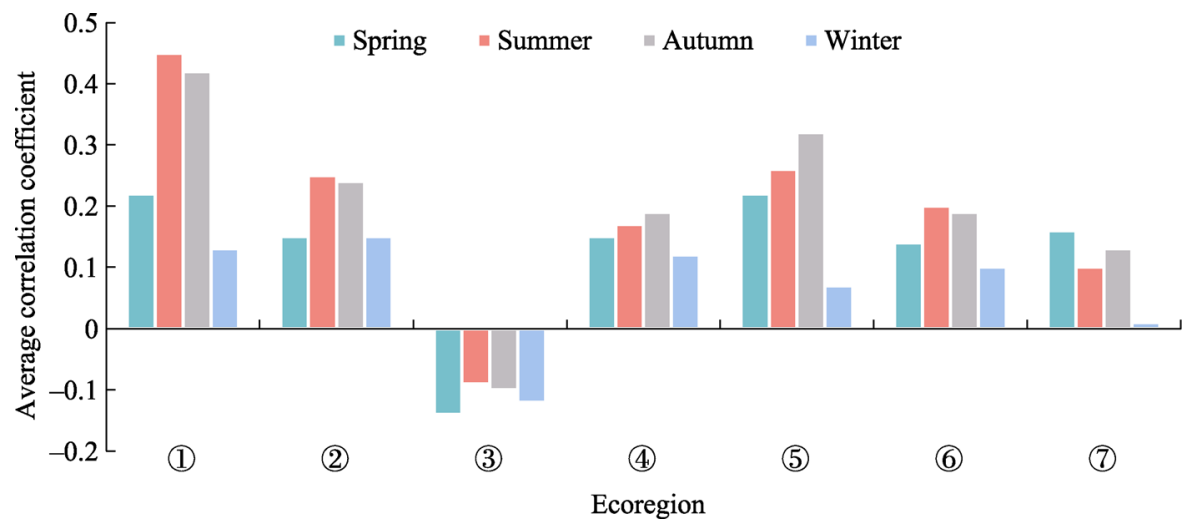

1) East Central Inner Mongolia Plateau Typical Steppe Ecoregion; 2) Yanshan-Taihang Mountain Deciduous Forest Ecoregion; 3) Tianjin-Beijing-Tangshan Urban and Suburban Agricultural Ecoregion; 4) North China Plain Agricultural Ecoregion; 5) Liaodong-Shandong Hilly Deciduous Broad-leaved Forest Ecoregion; 6) Qinling-Daba Mountains Deciduous and Evergreen Broad-leaved Forest Ecoregion; 7) Huaiyang Hilly Evergreen Broad-leaved Forest Ecoregion

Figure 9 Average correlation between vegetation coverage and PDSI in different seasons in North China

\section{Conclusions and discussion}

\subsection{Conclusions}

(1) Vegetation coverage in the southern part of the North China Plain was higher than that 
in the north. The vegetation coverage in the central region was higher than in the surrounding area. Among these areas, the highest degree of vegetation coverage occurred in the Huaiyang hilly evergreen broad-leaved forest ecoregion, the lowest occurred in the eastern region of the Inner Mongolian Plateau typical steppe ecoregion.

(2) From 2001 to 2013, the vegetation coverage in the North China Plain showed an overall upward trend. Around the North China Plain, to the north, west, and south and in the mountainous foothills, the vegetation coverage increased, while in the agricultural areas of the North China Plain, Beijing, Tianjin suburban areas, and coastal regions of Shandong Province, vegetation coverage decreased. Vegetation coverage exhibited an upward trend inside the city of Beijing, Tianjin and others.

(3) From 2001 to 2013, the northeastern region of North China became wet, and the southern region became arid. Drought conditions in the Inner Mongolian steppe region and North China Plain in the central, eastern, and southwestern Liaoning-Shandong hilly area did not change significantly.

(4) It can be seen from the results of the annual analysis that vegetation coverage and the extent of drought in North China were generally positively correlated, the most obvious being the northwestern North China areas, including the Inner Mongolian typical steppe area, agricultural area in the central North China Plain and the Liaodong-mountainous region in southwestern Shandong. Primary and secondary urban agglomerations in North China exhibited negative regional correlation coefficients; these regions have been severely disturbed by human activities, and there was a weak correlation between vegetation coverage and climate-related drought conditions.

(5) In most parts of the north, it is obvious that the extent of summer and autumn drought was related to vegetation coverage. The vegetation coverage response to the extent of the drought in spring, summer and autumn was relatively low, but in the southeastern North China Plain and agricultural areas in North China, correlation coefficients were lower in spring, summer, and autumn.

\subsection{Discussion}

Taking into account that during the vegetation growing season, the vegetation coverage and drought conditions showed a significant linear relationship (Mu et al., 2012), the monthly vegetation coverage and PDSI correlation analysis were not presented in this article.

This study analyzed vegetation coverage in the ecoregions of North China in response to the extent of drought conditions. Under natural conditions, the vegetation coverage in most parts was positively correlated with the change in drought. The correlations with vegetation cover types were high. The typical steppe responded most strongly to the drought conditions, followed by the northern forest areas, farmland, and the southern forest region.

The average temperature of the Inner Mongolian grassland ecoregion is low, precipitation is low and is concentrated in summer; this area is drought-prone, with low field capacity, and sufficient heat and rainfall are the main factors contributing to the drought (Mu et al., 2012). In this area, PDSI can better estimate drought conditions.

Surface drought in the North China Plain agricultural areas mainly depends on summer precipitation and artificial practices aimed to improve water availability. This study focused on the crop growing season from May to October; in the North China region, May to Octo- 
ber is the cotton growing season and June to September is the summer crop growing season, e.g., corn. Summer crops are sown, and the abundant rainfall during this period together with the temperature increase result in the highest potential evapotranspiration of the year (Liu et al., 2010), which likely exceeds rainfall. In this agricultural area, although frequent irrigation is used, which affects the drought conditions, there is also strong correlation between the growth rate of a large number of crops and potential evapotranspiration and precipitation.

Human activities have a strong impact on vegetation coverage and surface drought conditions. The 13-year PDSI data from the urban and suburban areas were not positively correlated with vegetation coverage. As the city expanded, the city boundary blurred, farmland was transformed into building land, and the vegetation coverage of the suburban areas decreased rapidly. In contrast, because of the extent of the urban greening rate, the proportion of vegetation coverage in urban cities has begun to increase (Yang et al., 2014). Construction activity has affected the impact of drought conditions on the rate of vegetation growth has been greatly reduced, and the change in vegetation coverage is not the dominant factor causing the drought conditions. Therefore, to analyze the vegetation cover in North China in the future, we should consider the impact of human activities on vegetation cover and changes in vegetation trends.

Altitude, topography, and other factors also affect the response of vegetation to drought conditions. Under high vegetation coverage and the abundant rainfall and warm climate in the mountainous Qinling-Daba and hilly Huaiyang ecoregions, changes in drought conditions over the short period of vegetation growth did not affect the average correlation coefficient, which was small. However, in ecological areas such as high altitude mountain areas, e.g., the western Henan mountains, vegetation coverage and PDSI was mostly positively correlated. The effect of elevation, topography and other factors on the vegetation coverage in North China remains to be studied.

\section{References}

An Shunqing, Xing Jiuxing, 1986. A Modified Palmer's Drought Index. Journal of Academy of Meteorological Science, 1(1): 75-82. (in Chinese)

Cui Linli, Shi Jun, 2012. Characteristics of seasonal response of NDVI to variations in temperature and precipitation in East China and its surrounding areas. Resources Science, 34(1): 81-90. (in Chinese)

Gan Chunying, Wang Xizhi, Li Baosheng et al., 2011. Changes of vegetation coverage during recent 18 years in Lianjiang River watershed. Scientia Geographica Sinica, 31(8): 1019-1024. (in Chinese)

Gu Tingmin, Zhu Ruizhao, Lin Zhiguang et al., 1991. Climate of North China Plain. Beijing: China Meteorological Press, 1-2. (in Chinese)

Han Haitao, Hu Wenchao, Chen Xuejun et al., 2009. Application and comparison of three meteorological drought indices. Agricultural Research in the Arid Areas, 27(1): 237-241, 247. (in Chinese)

Holben Brent N, 1986. Characteristics of maximum-value composite images from temporal AVHRR data. International Journal of Remote Sensing, 7(11): 1471-1434.

Kuang Shengshun, 1991. The horizontal zonation distribution of vegetation in Henan. Journal of Wuhan Botanical Research, (2): 153-160. (in Chinese)

Li Dengke, Fan Jianzhong, Wang Juan, 2010. Change characteristics and their causes of fractional vegetation coverage (FVC) in Shanxi Province. Chinese Journal of Applied Ecology, 21(11): 2896-2903. (in Chinese)

Liu Bin, Sun Yanling, Wang Zhongliang et al., 2015. Analysis on the relative effects of vegetation cover change 
and its influence factors in North China. Journal of Natural Resources, 30(1): 12-23.

Liu Lian, Zhang Yuming, Wang Shouyi et al., 1996. Hebei Vegetation. Beijing: Science Press. (in Chinese)

Liu Weiwei, An Shunqing, Liu Gengshan et al., 2004. The farther modification of Palmer Drought Severity Model. Journal of Applied Meteorological Science, 15(2): 207-216. (in Chinese)

Liu Yu, Cai Lingen, 1997. Update definition and computation of reference evapotranspiration comparison with former method. Journal of Hydraulic Engineering, 6: 27-33. (in Chinese)

Liu Yuan, Wang Ying, Yang Xiaoguang, 2010.Trends in reference crop evapotranspiration and possible climatic factors in the North China Plain. Acta Ecologica Sinica, 30(4): 923-932. (in Chinese)

Ma Zongjin, Fang Weiqing, Gao Qinghua et al., 1993. Major Natural Disasters and Countermeasures of Disaster Release in China (Theory). Beijing: Science Press. (in Chinese)

Meteorological Reference Room, National Meteorological Information Center. China Meteorological Data Sharing Service System. http://cdc.cma.gov.cn/.

$\mathrm{Mu}$ Shaojie, Li Jianlong, Chen Yizhao et al., 2012. Spatial Differences of Variations of Vegetation Coverage in Inner Mongolia during 2001-2010. Acta Geographica Sinica, 67(9): 1255-1268. (in Chinese)

Omuto C T, Vargas R R, Alim M S et al., 2010. Mixed-effects modelling of time series NDVI-rainfall relationship for detecting human-induced loss of vegetation cover in drylands. Journal of Arid Environments, 74(11): 1552-1563.

Palmer W C. Meteorological Drought. Research Paper No.45. Washington DC: U.S. Department of Commerce Weather Bureau, 1965.

Piao Shilong, Fang Jingyun, 2001. Dynamic vegetation cover change over the last 18 years in China. Quaternary Sciences, 21(4): 294-302. (in Chinese)

Research Center for Eco-Environmental Sciences, 2014. Chinese Academy of Sciences. China ecosystem assessment and ecological security database. http://www.ecosystem.csdb.cn/.

Sun Shizhou, 1998. Concerning the Vegetation Chinese Regionalization Map as a part of in the Natural Geographical Atlas of the Peoples Republic of China. Chinese Journal of Plant Ecology, 22(6): 523-537. (in Chinese)

Sun Yanling, Guo Peng, 2012. Spatiotemporal variation of vegetation coverage index in North China during the period from 1982 to 2006. Arid Zone Research, 29(2): 187-193. (in Chinese)

Wang J, Rich P M, Price K P, 2003. Temporal responses of NDVI to precipitation and temperature in the central Great Plains, USA. International Journal of Remote Sensing, 24(11): 2345-2364.

Wang Yi, Tan Yanjing, 2014. Research on the variation of vegetation ndvi and its relationship with climatic factors in northern china. Journal of Shanxi Agricultural Sciences, 42(8): 890-895. (in Chinese)

Wei Jie, Ma Zhuguo, 2003. Comparison of Palmer Drought Severity Index, percentage of precipitation anomaly and surface humid index. Acta Geographica Sinica, 58(Suppl.1): 117-124. (in Chinese)

Wei Jie, Tao Shiyan, Zhang Qingyun, 2003. Analysis of drought in northern China based on the Palmer Severity Drought Index. Acta Geographica Sinica, 58(Suppl.1): 91-99. (in Chinese)

Wu Zhengyi, Wang Xianpu, Liu Fangxun et al., 1980. China Vegetation. Beijing: Science Press. (in Chinese)

Yang Jun, Huang Conghong, Zhang Zhiyong et al., 2014. The temporal trend of urban green coverage in major Chinese cities between 1990 and 2010. Urban Forestry \& Urban Greening, 13(1): 19-27. (in Chinese)

Yu Fangfang, Pricea Kevin P, Ellis James et al., 2003. Response of seasonal vegetation development to climatic variations in eastern central Asia. Remote Sensing of Environment, 87(1): 42-54.

Zhang Yichi, Wu Kai, Yu Jingjie et al., 2011. Characteristics of precipitation and air temperature variation during 1951-2009 in North China. Journal of Natural Resources, 26(11): 1930-1941. (in Chinese)

Zheng Jingyun, Ying Yunhe, Li Bingyuan et al., 2010. A new scheme for climate regionalization in China. Acta Geographica Sinica, 65(1): 3-12. (in Chinese)

Zheng Youfei, Liu Hongju, Wu Rongjun et al., 2009. The change of NDVI in Guizhou Province and its relationship with major climatic factors. Chinese Journal of Ecology and Rural Environment, 25(1): 12-17. (in Chinese) 